\title{
Inversão, desnaturalização e reforço de práticas de gênero em peças publicitárias
}

\section{Laura Guimarães Corrêa}

Doutora; Universidade Federal de Minas Gerais

guimaraes.laura@gmail.com

\section{André Melo Mendes}

Doutor; Universidade Federal de Minas Gerais

andremelomendes@hotmail.com

\section{Resumo}

O artigo tem como objetivo apresentar uma discussão sobre gênero e feminismo vinculada à análise de três peças publicitárias brasileiras que propõem práticas e discursos que se diferenciam das práticas e discursos tradicionais em que predomina uma abordagem machista. Os comerciais analisados promovem produtos de limpeza e divulgam o lançamento de um carro. Nessas peças, as mulheres são apresentadas como pessoas distantes do trabalho doméstico, enquanto as tarefas de casa são executadas por homens. Trata-se de mudança significativa, se consideradas as representações de gênero correntes da publicidade brasileira. Nota-se, entretanto, a manutenção de relações desiguais e hierárquicas, em que apenas o vetor é mudado, mantendo-se a tradicional configuração heteronormativa e a estrutura dicotômica de divisão valorativa do trabalho baseada no gênero.

\section{Palavras-chave}

Publicidade. Feminismo. Divisão do trabalho. Práticas de Gênero.

\section{Introdução}

Apesar dos diversos avanços no campo social e das ideias, a visada em direção às representações de gênero nos media e às pesquisas sobre o tema confirma o caráter machista preponderante nos discursos que perpassam a complexa e diversa sociedade brasileira na contemporaneidade. Dados estatísticos e acontecimentos cotidianos também 
apontam para essa insidiosa característica da nossa população. Quanto à esfera do trabalho, tema presente nos comerciais, dados do Instituto Brasileiro de Geografia e Estatística - IBGE (2014) mostram que o rendimento médio mensal das mulheres é $27,1 \%$ menor do que o dos homens. Elas ocupam cargos com remunerações mais baixas do que os homens, como os trabalhos domésticos e, mesmo desempenhando a mesma função, recebem menos. Além disso, a taxa de desemprego é 36,5\% maior entre as mulheres do que entre os homens.

O Brasil é um dos poucos países ocidentais em que o aborto é criminalizado, mesmo em casos excepcionais que legalizam a interrupção da gravidez na maioria dos estados laicos. Os índices de violência doméstica são assustadores, assim como casos de crimes provocados por ideias sexistas, misóginas e homofóbicas. Apesar da reeleição de uma mulher para a presidência do País, temos uma das taxas mais baixas do mundo em número de mulheres que ocupam cargos políticos elegíveis.

Argumenta-se, contra as ideias igualitárias feministas, que as mulheres do século XXI já conseguiram tudo o que queriam (trabalho remunerado, independência financeira e liberdade sexual). Assim, não haveria mais sentido em reivindicar direitos. Apesar das conquistas femininas no mundo ocidental, nas últimas décadas, operadas por movimentos sociais, principalmente o(s) movimento(s) feminista(s), mantêm-se situações de desigualdade de gênero em graus variados, mesmo neste terceiro milênio.

A análise de produtos publicitários pode contribuir para a discussão sobre o movimento dos valores sociais relacionados ao gênero. Entendemos a publicidade como um sistema simbólico que ao mesmo tempo constitui e é constituído pela sociedade em que vivemos. Não se deve pensar a publicidade, ou a comunicação, como instância descolada da sociedade. Como produto construído por e para pessoas em sociedade, as peças publicitárias refletem e reforçam construções sociais compartilhadas, assim como também podem propor rupturas e transformações por meio de discursos e práticas dos indivíduos representados. 
Figura 1 - Anúncio da Volkswagen para o Fusca (década de 1960)

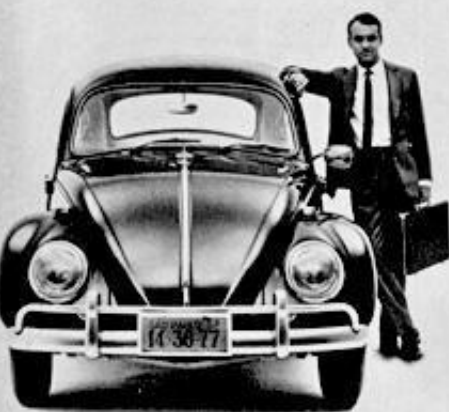

Êle

de manhã vai ao trabalho $\theta$ volta à noite.

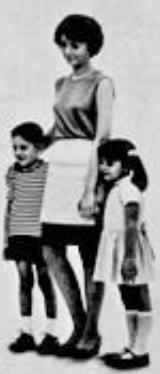

Ela

leva as crianças à escola

vai a feira, vai ao cabeleireiro, vai buscar mamãe busca

as criancas da escola, busca os

sobrinhos para brincarem

sobrinhos para brincarem
escr as criancas que voltaram da
escola, vai à costureira,

escola. var a costureira,
leva mamåe para casa, vai fazer

compras na cidade,

devolve os sobrinhos, vai visitat

as amigas, vai ver como

itia Celina esta passando, volta à casa

V) de uma amiga para

(W) apanhar a bólsa que tinh

esquecido etc. otc. etc.

Não é justo que ela tenha

um Volkswagen só para ela?

Fonte: História da Publicidade (2009, documento eletrônico não paginado).

Nesse contexto, as peças de comunicação publicitária produzidas e distribuídas no País historicamente se caracterizaram por mostrar as relações de gênero baseadas em estereótipos, nos quais à mulher estão destinados os trabalhos do lar, do cuidado das crianças e de outras pessoas (como no antigo anúncio da Volkswagen reproduzido acima a título de ilustração) e o papel de objeto do desejo masculino, disponível ao lado dos produtos oferecidos ao consumo. Em comerciais de cerveja e carros produzidos nos últimos anos, por exemplo, homens ocupam lugares de poder enquanto mulheres têm sido retratadas como coadjuvantes ou prêmios a serem desfrutados pelos homens diretamente relacionados ao consumo desses produtos.

Aos homens, a publicidade tem destinado, principalmente, o trabalho fora de casa, assim como o papel de bons provedores ou de merecedores e apreciadores de bons produtos - e de belas mulheres. Nas últimas décadas, "comercial de margarina" chegou a tornar-se uma expressão coloquial para designar aquelas situações idealizadas de um lar perfeito construído na publicidade: o pai branco está vestido para ir trabalhar, as crianças 
loiras são sorridentes e a mãe, magra, jovem, branca e penteada logo cedo, serve com alegria o café da manhã para a família.

Considerando não só uma sociedade machista, mas uma publicidade conservadora e heteronormativa como contexto, três filmes publicitários veiculados entre 2009 e 2013 nos chamaram a atenção ao apresentar relações de gênero (entre homens e mulheres) de forma não usual. Antes de procedermos à análise dessas peças, faremos um breve panorama do pensamento sobre gênero e feminismo a partir da segunda metade do século XX, que nos servirá como instrumental para a reflexão acerca dos comerciais ${ }^{1}$. Após o panorama teórico, apresentamos as peças e a interpretação que elaboramos, utilizando como metodologia principal um método de base semiótica desenvolvido por Mendes (2011). Esse método leva em consideração que a maneira como os comerciais constroem suas narrativas depende não apenas do conteúdo veiculado no texto falado pelos personagens ou destacados no vídeo, mas incluem também o uso de imagens, som ambiente entre outros recursos expressivos.

O percurso metodológico se constitui basicamente em dois momentos: um objetivo e outro subjetivo, cuja legitimidade das afirmações e reflexões deve estar ancorada no primeiro momento. Na etapa objetiva são consideradas as qualidades formais dos signos e suas características, além do contexto histórico em que estão situados. Nessa fase são avaliadas também as relações retóricas entre elementos em diversas linguagens. Com essa metodologia pretende-se evitar a circularidade interpretativa e a superficialidade das análises. Nesse artigo, cada comercial foi analisado individualmente e, na conclusão, as análises foram cruzadas.

\section{Sobre gênero}

Com a publicação de $O$ segundo sexo em 1949, Simone de Beauvoir causou polêmica e provocou importantes reflexões ao chamar a atenção para a condição feminina. No livro, dividido em duas partes, a autora destacou as dimensões sociais, psicológicas, culturais e políticas da desigualdade entre homens e mulheres. Referência até os dias atuais, a obra trouxe contribuições fundamentais para o pensamento sobre a história, os mitos, as práticas, os papéis sociais e, principalmente, as relações de poder entre mulheres e homens. Suas reflexões são anteriores ao conceito de gênero, que pôde emergir a partir da vereda aberta por Beauvoir.

${ }^{1}$ Esse panorama é baseado em pesquisa anterior de Corrêa (2011). 
A autora abre a segunda parte da obra com a célebre frase "Ninguém nasce mulher: torna-se mulher". (BEAUVOIR, 2009, p. 361), questionando assim o essencialismo biológico que, por muito tempo, justificou e tem justificado a diferença hierárquica entre os seres sexuados, apontando para o aspecto histórico e cultural das definições do feminino e do masculino. Ao defender o caráter social, relacional, construído e aprendido da diferença entre homens e mulheres, Beauvoir (2009) lançou a semente de um pensamento, retomado na segunda metade do século XX por feministas, tais como Joan Scott, Donna Haraway e Judith Butler, entre outras.

A historiadora Joan Scott (1986) defende a noção de gênero no importante artigo Gênero: uma categoria útil para a análise histórica. A autora o define como “[...] uma maneira de referir-se à organização social da relação entre os sexos"2. (SCOTT, 1986, p. 1053, tradução nossa). 0 termo explicita o caráter relacional das questões que envolvem os seres sexuados, negando as definições de homem e mulher baseadas exclusivamente na biologia e na diferença física. Para a autora, o "Gênero é um elemento constitutivo das relações sociais baseadas em diferenças percebidas entre os sexos, e gênero é um modo primário de significar relações de poder"3. (SCOTT, 1986, p. 1067, tradução nossa).

As questões de gênero, articuladas com as relações de poder, colocam em evidência aspectos importantes para a compreensão dos mais diversos fenômenos sociais. Essa premissa tem consequências teóricas e metodológicas: as práticas femininas não devem ser estudadas isoladamente, pois demandam também a pesquisa sobre as práticas masculinas, pois entendemos esses sujeitos como agentes em interação.

Para Scott (1986), o gênero envolve quatro elementos inter-relacionados: símbolos, conceitos normativos, instituições e identidades. É possível articular todos esses elementos apontados para a reflexão sobre os discursos publicitários que tematizam as relações entre mulheres e homens. A publicidade se utiliza de símbolos compartilhados na cultura, reafirma ou contesta normas que sustentam as instituições, assim como está diretamente relacionada à formação dos sujeitos e à construção das identidades.

Segundo Donna Haraway, "Gênero é um conceito desenvolvido para contestar a naturalização da diferença sexual em múltiplos terrenos de luta”. (HARAWAY, 1995, p. 221 apud LOURO, 2002, p. 229). Assim sendo, o conceito de gênero é político e estratégico: sexo

\footnotetext{
${ }^{2}$ No original: "[...] a way of referring to the social organization of the relationship between the sexes".

3 "Gender is a constitutive element of social relationships based on perceived differences between the sexes, and gender is a primary way of signifying relationships of power".

${ }^{4}$ HARAWAY, Donna. Ciencia, cyborgs y mujeres: la reinvención de la naturaleza. Madrid: Ediciones Cátedra, 1995.
} 
é um conceito ligado a determinadas características e diferenças físicas dos seres humanos, e gênero seria aquilo que é definido cultural e socialmente a partir de tais características. 0 sexo seria, então, dado pela conformação natural do ser humano, enquanto o gênero é entendido como uma construção social, que vai além da biologia.

Judith Butler (1999) entende que o gênero é reafirmado constantemente durante a vida dos seres sexuados, tornando cada vez mais "natural" aquilo que é aprendido socialmente através de interpelações cotidianas diversas. Com inspiração beauvoriana e avançando com a discussão, Butler afirma que:

A garota torna-se uma garota, ela é trazida para o domínio da linguagem e do parentesco através da interpelação do gênero. Mas esse tornar-se garota da garota não termina ali, pelo contrário, essa interpelação fundante é reiterada por várias autoridades, e ao longo de vários intervalos de tempo, para reforçar ou contestar esse efeito naturalizado. (BUTLER, 1999, p. 161, grifos nossos).

O foco dessa reflexão encontra-se na problematização de concepções solidificadas de sexo, gênero e sexualidade, e no questionamento de uma normatividade heterossexual binária (homem/mulher) reprodutiva. Como afirma Butler (1999), as identidades de gênero são mais dinâmicas e plurais do que pretende a classificação dualista. Há cada vez mais misturas, indefinições e ambiguidades nas formas pelas quais os sujeitos experienciam o sexo, a sexualidade e o gênero.

O ser sexuado a quem se convencionou chamar "mulher" é uma categoria abrangente e heterogênea, que constitui minoria no sentido apresentado por Muniz Sodré (2005) para o conceito. $\mathrm{O}$ autor define o grupo minoritário não em termos quantitativos, mas em termos políticos, como aquele que esteve calado, sem fala, e que passa a se expressar na direção de uma transformação política.

O grupo social "mulheres" tem sido marcado por uma histórica opressão e desvalorização baseadas na diferença, como um desvio do padrão não marcado "homem". Historicamente, os discursos mais autorizados em nossa sociedade, assim como as instituições mais valorizadas têm sido majoritariamente formadas por homens. Essa configuração social só pode ser enfrentada e transformada através de embates entre grupos e indivíduos no terreno do discurso e da cultura.

É nesse terreno agonístico que se inscrevem, por exemplo, os movimentos feministas, as teorias de gênero, a mobilização contra a homofobia e as disputas de sentido. Para Braidotti, "Negar uma difamação de vários séculos, para acercar-se do limiar de uma 
redefinição da mulher, é o salto discursivo para diante dado pelo feminismo como movimento de pensamento e ação". (BRAIDOTTI, 1997, p. 142).

Um embate importante é a própria luta por legitimidade desses movimentos e teorias. Mesmo nos dias atuais, nota-se a desvalorização no senso comum e mesmo nos meios acadêmicos ao projeto do feminismo. É dito, por exemplo, que a busca pela igualdade seria um tipo de "masculinismo", raciocínio que faria sentido apenas se a categoria "homem" fosse eleita como norma, referência e exemplo a seguir. A igualdade em questão refere-se a uma simetria e equivalência de direitos, deveres, oportunidades e responsabilidades e não a uma tentativa de arremedo do masculino.

No senso comum, o feminismo é, por vezes, erroneamente entendido como um projeto de dominação feminina, ou seja, como o oposto do "machismo", que é definido por Sandra Azerêdo (2007, p. 119) como "[...] o conjunto de valores e normas que têm como objetivos manter privilégios dos homens em detrimento dos direitos das mulheres, considerando estas como naturalmente inferiores àqueles". Essa equivalência entre feminismo e machismo obviamente não se aplica à realidade, pois as teorias e os movimentos feministas estão baseados no conceito de direitos humanos universais, combatendo exatamente o sexismo, ou seja, a hierarquia e a opressão baseadas em sexo, gênero e sexualidade. As diversas vertentes do feminismo têm em comum o projeto e a vontade de transformação nas relações desiguais de gênero.

Ao longo das últimas décadas, as práticas das mulheres têm se tornado mais diversas e complexas. A inserção da população feminina no mercado de trabalho extradoméstico, nos mais diversos segmentos da sociedade, trouxe novas configurações que refletem no cotidiano de mulheres e de homens, gerando maior autonomia financeira e, ao mesmo tempo, dificuldades com o acúmulo de tarefas e responsabilidades na esfera feminina. Como lembra Perrot (2005), ao longo da história da humanidade, as mulheres sempre trabalharam. Entretanto, o trabalho feminino remunerado e fora de casa, necessário ao funcionamento do sistema capitalista atual, gera um desencaixe nas relações de gênero, principalmente no que diz respeito ao cuidado das crianças e das pessoas dependentes.

A participação dos homens no trabalho doméstico tem sido uma das importantes bandeiras das mulheres desde a chamada segunda onda do feminismo, que tinha como um de seus slogans a frase "o pessoal é político" - isto é: as relações e práticas que se dão na esfera privada, familiar, dentro de casa, estão intimamente conectadas às reivindicações e 
conquistas no universo da política, do trabalho extra doméstico, da saúde, do cuidado e da educação.

Diante de tais apontamentos, veem-se hoje diversos modelos e valores para o feminino e para o masculino - muitas vezes contraditórios - construídos e oferecidos nas interações midiáticas e, especialmente, na publicidade.

\section{Três comerciais e as questões que suscitam}

Neste artigo, pretendemos analisar dois comerciais do limpador Veja Multiuso Ação e Proteção, veiculados no ano de 2013, em que há a desconstrução da imagem do "macho" que não põe o pé (muito menos as mãos) na cozinha, além do comercial de lançamento do veículo Novo Idea, da Fiat, veiculado em 20115. Mesmo se tratando de produtos diferentes, a escolha desses comerciais se justifica pelas inversões de práticas tradicionais de gênero realizadas e exploradas nessas propagandas. Em geral, carros são produtos anunciados para um público tipicamente masculino, enquanto produtos de limpeza destinam-se ao feminino. Os três comerciais invertem valores arraigados como estratégia para chamar a atenção, produzir humor e gerar aceitação pelo potencial público consumidor.

Há muitos anos, os comerciais de limpeza têm presença garantida na televisão brasileira, sempre trabalhando com uma lógica higienista exacerbada. Em sua maioria, as donas de casa- geralmente mães- são apresentadas como pessoas obcecadas por limpeza e pela proteção de toda a família. Uma sujeira ou mancha, nesses comerciais, são vistas como algo abominável, com toques de drama. 0 produto salvador devolve o "branco" ao espaço doméstico, o que costuma gerar na mulher uma expressão de felicidade intensa. É raro na publicidade brasileira que um homem ou um pai de família apareça cuidando da casa. Esses são pontos comuns no comercial padrão de produtos de limpeza: desodorizadores de ambiente, inseticidas, sachês para banheiro, limpadores, sabonetes antibacterianos, sabões em pó, entre outros itens.

Nessas peças, o mundo externo da rua e dos microrganismos prejudiciais à saúde é mostrado como algo muito perigoso e que deve ser evitado, tal como um inimigo que deve ser combatido com a ajuda de produtos químicos que desinfetam e protegem a casa, os adultos, as crianças e até os animais domésticos. A obsessão da sociedade do consumo por

\footnotetext{
${ }^{5}$ Agradecemos à Fernanda Miranda a identificação e localização desse comercial. Disponível em: <https://www.youtube.com/watch?v=pEm0oEfmuf8>. Acesso em 12 mar. 2014.
} 
higiene, assepsia, esterilização, já observada por Jean Baudrillard em 1970, era personificada em personagens mulheres (BAUDRILLARD, 1995).

Nos últimos anos, a série de vídeos produzida para divulgar o produto Veja tem adotado uma postura diferente. Desde 2008, para a comunicação publicitária do limpador, foi criada a personagem Neura, uma versão em preto e branco, neurótica e malvestida da dona de casa. A Neura instiga a mulher a se sacrificar pela limpeza da casa. Essa, por sua vez, não se abala e resolve o problema, tranquilamente, graças ao uso do produto. No discurso desses comerciais, o tom educativo e impositivo comum na publicidade de produtos de limpeza é parodiado e substituído pelo humor, para se divulgar uma ideia um pouco menos conservadora das relações entre homem e mulher. Além disso, o discurso veiculado no comercial do limpador Veja também procura desconstruir a suposta fixação da dona de casa por limpeza, sugerindo que a mulher tem direito a descansar, a se arrumar e se divertir.

No comercial Neuro $^{6}$, de 30 segundos, temos uma situação em que a família é composta apenas por um casal. 0 cenário é a copa/cozinha de uma casa impecavelmente limpa, com o chão branco. A caracterização da cozinha (aberta, com exaustor e geladeira de design sofisticado) sugere que os personagens são um casal com poder aquisitivo acima da média, suposição reforçada pelos objetos de cena e pelo figurino. A mesa do café está posta com cuidado e não fica claro quem a arrumou - ao contrário dos comerciais de margarina, em que a mulher-mãe põe a mesa para a família.

A mulher tem os cabelos curtos, veste calças compridas e um terno de corte feminino: uma roupa prática, formal e que deixa clara a sua atividade de trabalho fora de casa. Ela usa uma elegante bolsa de couro e sua camisa é rosada, cor associada ao feminino. 0 homem também usa uma roupa formal, mas incompleta: calça e camisa sociais, que podem ser acrescentadas de um terno quando ele se dirigir ao trabalho. Sua camisa azul está presa para dentro da calça e seu cabelo está bem cortado e penteado, em estilo formal e comportado. Os dois trabalham fora, mas o uso das cores segue as normas tradicionais para o gênero: rosa para meninas, azul para meninos.

\footnotetext{
6 VEJA: Veja Ação e Proteção em Neuro (2014). Disponível em: <https://www.youtube.com/watch?v=5L7cGxlpAPU> Acesso em: 07 maio 2015.
} 
Figura 2 - Frames do comercial de Veja Multiuso (Neuro)
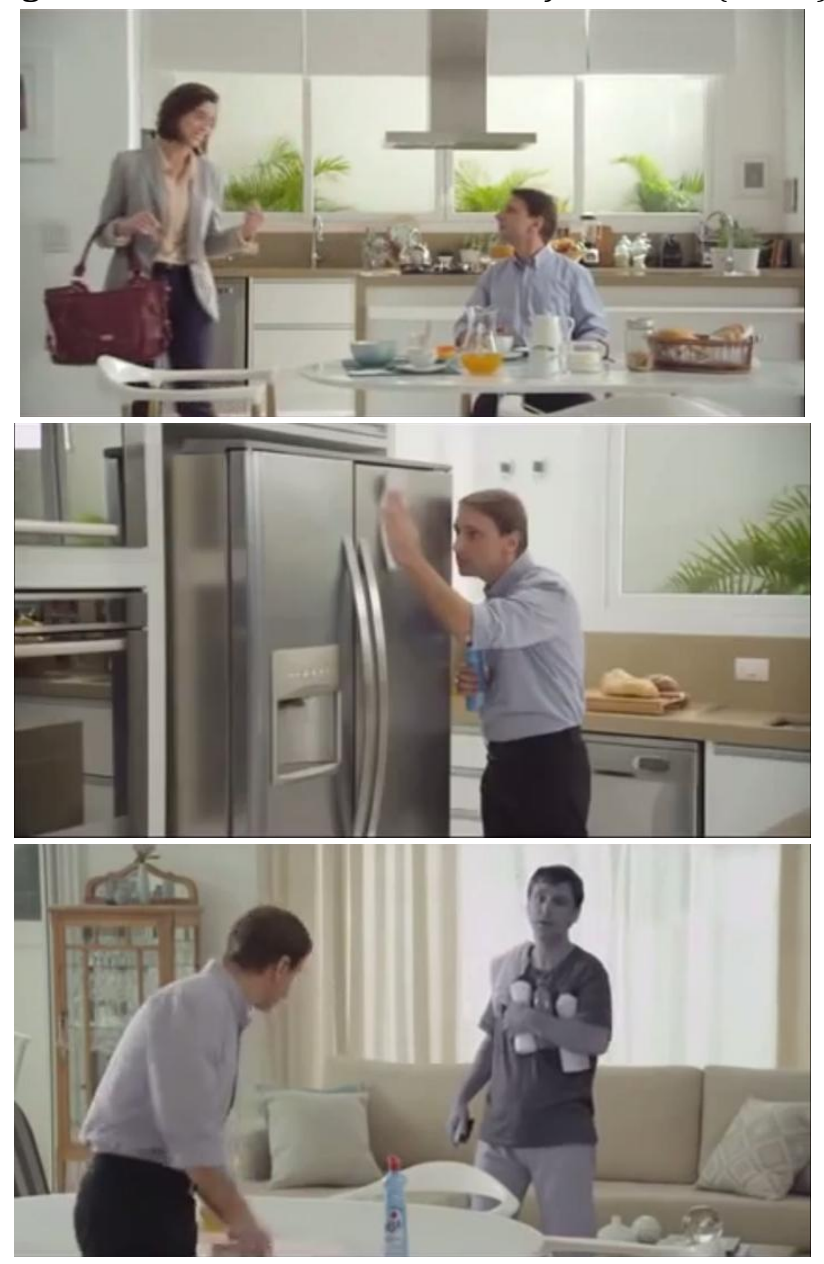

Fonte: Veja Ação e Proteção em Neuro (2014).

É notável, também, a referência à cultura americana: utilização de cozinha ampla e sem parede para dividir a copa. Essa mudança na arquitetura da casa é relacionada ao fato de que, nessa cultura, os custos para se manter uma empregada doméstica são muito altos, mesmo para classes privilegiadas. Isso implica no uso da cozinha pelos próprios donos da casa, o que justifica o investimento em aparelhos e decoração moderna. Além disso, o deslocamento da cozinha para a copa deve ser prático, já que não há mais serviçais. A adoção dessa configuração está relacionada à intenção de reforçar a ideia de modernidade proposta para o produto.

No esquete, a mulher, pronta para sair, deixa cair uma torrada com creme e geleia no chão, diz carinhosamente ao marido que está atrasada e se despede. 0 incrédulo homem parece não saber bem o que fazer diante da situação. Ele coça a cabeça e, depois desse momento de hesitação, descobre o produto Veja e suas propriedades maravilhosas que 
permitem que ele limpe tão bem quanto sua mulher. O Neuro diz: "Ih, a sua mulher faz isso melhor que você", reafirmando um jargão machista tradicional, mas que é logo rechaçado pelo homem "moderno" que responde: "Neuro, evolui". Assim, o homem faz desaparecer o fantasma com um esguicho de Veja. No packshot com a imagem do produto, o slogan é escrito e falado: "Veja Ação e Proteção: a limpeza nunca mais será a mesma".

O personagem Neuro é uma versão masculina do personagem feminino Neura, que, por sua vez, é uma alegoria do fantasma que perseguiria as mulheres ao impor e cobrar um cuidado excessivo com a limpeza da casa. 0 personagem masculino veste roupas simples, adequadas à prática da faxina e sua imagem está em preto e branco, num claro contraste com sua versão colorida de homem pronto para o trabalho executivo. Além de caracterizado negativamente pelas roupas e sua cor cinzenta, o Neuro carrega três produtos de limpeza, enquanto sua versão competente necessita de apenas alguns segundos e um único e prático produto para realizar sua tarefa.

A ousadia do comercial não está em mostrar uma mulher que tem compromisso fora de casa e que está atrasada para cumpri-lo, mas em ilustrar uma mulher que não se importa em deixar o chão da cozinha sujo, ou seja, que não é naturalmente obcecada com a limpeza. O homem, apesar de surpreso com a atitude da mulher, termina por limpar o chão - tarefa considerada no Brasil como obrigação das donas de casa ou das empregadas domésticas. 0 texto do comercial reforça uma habilidade superior feminina para a limpeza, supostamente natural, quando afirma que o homem não deve se preocupar em limpar "melhor" do que a mulher. Ao mesmo tempo, a peça critica esse preconceito ao apresentar ao público uma situação oposta àquela que o senso comum diz sobre práticas adequadas e naturalizadas para homens e mulheres.

A referida publicidade, como a maioria televisionada, mostra um casal branco, jovem, heterossexual e rico, mas escapa da reprodução do estereótipo de constituição familiar, ao apresentar um par que, aparentemente, não tem filhos(as), mesmo numa faixa etária em que poderia tê-los.

Já no comercial Macho $\mathrm{Alfa}^{7}$, para o mesmo produto, observa-se a desconstrução, por via irônica, do conceito derivado da biologia e muito difundido na atualidade, no qual o homem que é nomeado como Alfa é considerado o líder do bando, o que significa que ele tem uma posição privilegiada no seu grupo, no que se refere à alimentação e às

\footnotetext{
7 VEJA: Caçadores de Neura em Macho Alfa (2014). Disponível em: <https://www.youtube.com/watch?v=fw1an6Linkc> Acesso em 07.05.2015.
} 
oportunidades sexuais. Para conquistar e se manter nessa posição distinta ele deve usar da força bruta para derrotar seus rivais e defender do bando ameaças potenciais. Nesse comercial de Veja, o homem se diz macho (alfa) exatamente pelo oposto do que ser macho significa na nossa sociedade.

Por meio dessa inversão, há uma valorização da sua masculinidade justamente por se encarregar das tarefas ditas "de mulher". Tanto na performance quanto em algumas das palavras utilizadas nesse monólogo, o homem está de acordo com as expectativas para o gênero masculino, de forma exagerada. Ele fala alto, gesticula e olha de forma agressiva para o público, agindo como uma pessoa autoritária, que tem ascendência sobre a mulher. As formas de enunciação - e de interação - provocam o estranhamento e o deslocamento por trazerem um conteúdo que inverte papéis tradicionais de gênero: esse homem, macho Alfa, é uma pessoa que cozinha para a mulher e cuida da limpeza da casa. 0 caráter de brincadeira do comercial é reforçado pela escolha do ator, um dos sócios do grupo de humor Porta dos Fundos, que desfruta de popularidade e prestígio na internet.

Figura 3 - Frame do comercial de Veja Multiuso (Macho Alfa)

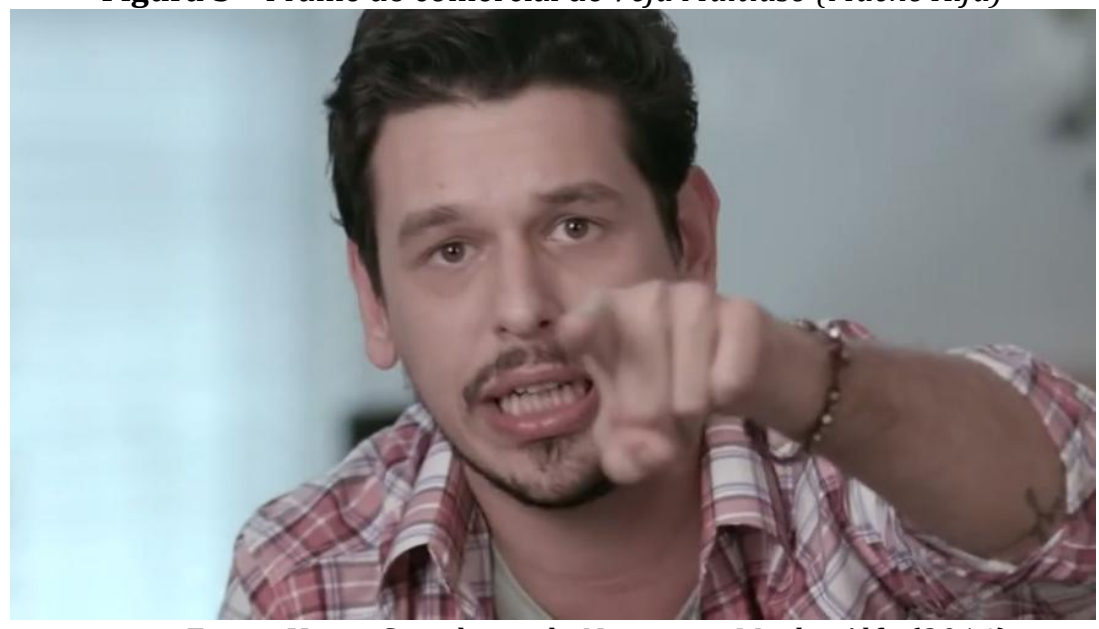

Fonte: Veja - Caçadores de Neura em Macho Alfa (2014).

Os personagens dos comerciais parecem ser representantes das classes privilegiadas brasileiras, nas quais a mulher que trabalha fora não executa muitas das tarefas domésticas, mas costuma ser a responsável pela organização do dia a dia familiar, controle da alimentação da família, compras e abastecimento da casa, contratação de empregados/as, administração do tempo e de tarefas, entre outras funções. A mulher segue sendo considerada a "rainha do lar", mesmo conquistando outros domínios. Os discursos de 
homenagem, que analisamos em outra ocasião ${ }^{8}$, contribuem para essa visão que coloca a mulher-mãe num falso pedestal. Os dois comerciais de Veja Multiuso apontam para uma direção contrária, em que a mulher não parece se importar tanto com a limpeza da casa, como seria comum às donas de casa tradicionais.

Na França do século XIX, as mulheres dos operários eram consideradas o "ministro do interior e das finanças", encarregadas de manter a ordem na casa, cuidar do orçamento doméstico e da educação das crianças (PERROT, 2005). Esse modelo, baseado no trabalho feminino de administração do espaço, da dinâmica e do orçamento domésticos, é bastante comum na cultura ocidental e reaparece em tempos e lugares diferentes.

Por vezes, os homens-pais são excluídos ou se excluem dos espaços do trabalho doméstico, com frases do tipo "homem na cozinha só atrapalha". Há inclusive, no senso comum, uma ridicularização do despreparo e incompetência masculina para o cuidado infantil ou da casa ${ }^{9}$. Essas tarefas são, por vezes, executadas com orgulho, diligência e exclusividade pelas mulheres-mães, e são valorizadas em discursos diversos como afirmação de feminilidade, como componente de uma "identidade feminina". É útil e ilustrativo lembrar a expressão "cuidar de marido", corrente no Brasil, usada para referir-se a uma das responsabilidades da mulher casada. Mas não é comum que se use o correspondente "cuidar de mulher" ou "cuidar de esposa" para a atividade do homem em relação à companheira. Há, com relação ao cuidado, ou care, uma expectativa de que a mulher seja "o adulto" frente aos outros membros da família, zelando pelo cuidado e pelo controle de toda a família. O comercial do Macho Alfa coloca o homem nessa posição de cuidado da casa e da mulher, em tom agressivo, numa performance que contradiz o discurso.

No comercial de lançamento do novo modelo do carro Novo Fiat Idea ${ }^{10}$, a mulher volta do trabalho e o homem está em casa, na cozinha, preparando e servindo uma refeição às filhas. A cozinha é semelhante àquela do casal do primeiro comercial analisado. 0 homem veste uma camiseta de malha cinza e calça jeans, uma espécie de "roupa de ficar em casa". Tudo se passa como se fosse uma família tradicional de comercial de margarina, até que a mulher, vestida com um terninho escuro (ou seja, uma roupa para trabalhar), diz para o

\footnotetext{
${ }^{8}$ Tese de doutorado "Mães cuidam, pais brincam: normas, valores e papéis na publicidade de homenagem", de Laura G. Corrêa (2011)

9 Medrado (1998) apresenta, no artigo Homens na arena do cuidado infantil: imagens veiculadas pela mídia, exemplos de anúncios publicitários que mostram esse pai trapalhão.

${ }^{10}$ NOVO Fiat Idea 2011: Comercial de lançamento no Brasil. 2010. Disponível em:

<http://www.youtube.com/watch?v=pEm0oEfmuf8>. Acesso em: 10 mar. 2014.
} 
companheiro: "Amor, vem ver a surpresa que eu tenho pra você!" e mostra as chaves de um carro que dá de presente ao marido. Às costas da mulher há uma área aberta que pertence à casa, reforçando a ideia de que a família possui elevado poder aquisitivo. As meninas correm animadamente na frente, seguidas pelo homem e a mulher. Enquanto ele experimenta o carro, ela descreve as qualidades do novo Idea: "Viu como é espaçoso? Dá pra levar as crianças na escola, fazer compras no supermercado, levar seus amigos no futebol...".

Essa fala confirma a inversão de papéis da cena anterior, em que a mulher presenteia o marido com um carro novo - ação tradicionalmente realizada por homens ricos que trabalham e têm condições financeiras para oferecer presentes caros às suas companheiras. Ao alterar essa distribuição de papéis, o objetivo do comercial é chamar a atenção, via exagero, para uma mudança na contemporaneidade e, assim, conquistar novos públicos. Quando o homem faz brincando a pergunta retórica "será que eu mereço?", podemos perceber quase uma caricatura do papel feminino. Na fala da mulher, nota-se que as atribuições do homem naquela família são como as da mulher na família tradicional, como no anúncio da Volkswagen da década de 1960 reproduzido anteriormente. A referência ao futebol de certa forma devolve ao homem a masculinidade perdida na inversão da divisão do trabalho na famíla. 
Figura 4 - Frames do comercial para o Novo Fiat Idea

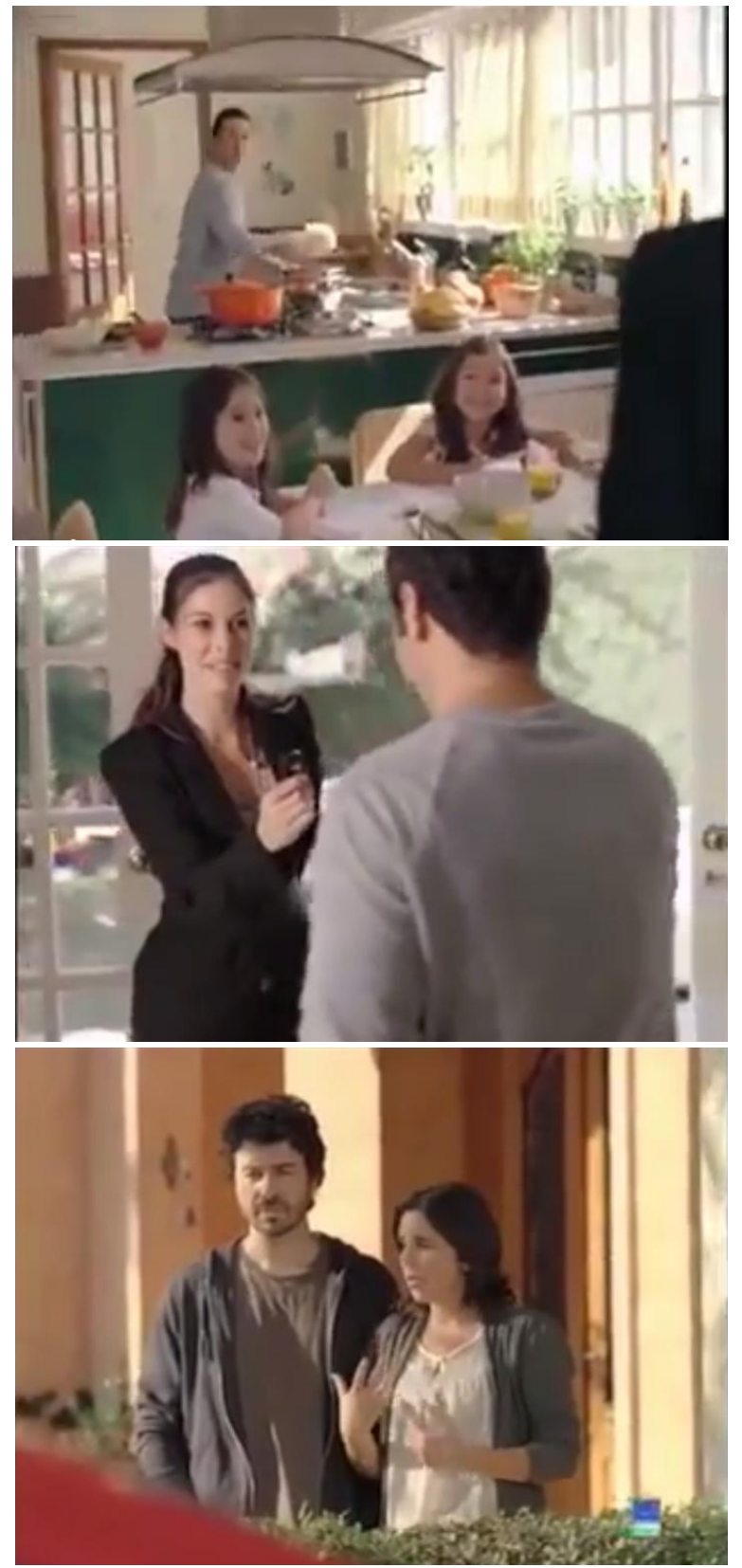

Fonte: NOVO Fiat Idea 2011- Comercial de lançamento no Brasil (2010).

A cena é observada por um casal de vizinhos, na qual o companheiro demonstra surpresa e inveja pela sorte do outro. A esposa parece tentar explicar: "amor..." ao que ele, contrariado e tristonho, responde que "precisa ficar um pouco sozinho." Mais uma vez, há inversão de práticas e estereótipos: o homem cobra da mulher um bom carro, como se a prática de prover e presentear fosse uma obrigação das mulheres. Se considerarmos os 
dados estatísticos sobre trabalho, gênero e remuneração no Brasil, essa inversão é pouco provável como regra, mas aponta para uma possibilidade.

Outro valor ativado no comercial é o de um sucesso pessoal e familiar (e até amoroso) que se revela pelo consumo, uma vez que a família que tem o carro é mais feliz do que a que não tem. Subjacente ao comercial, há o reforço da competição gerada pelo status adquirido por meio do consumo do automóvel, elemento simbólico relevante socialmente.

Nas cenas externas do comercial, observa-se a ausência de muros altos, como é comum nas casas de subúrbio norte-americanas. Essa característica é o que permite que o casal vizinho presencie o momento em que o marido é presenteado com um carro pela esposa. Na configuração atual das casas de classe média alta na paisagem urbana brasileira, a realização dessa cena seria mais difícil, a não ser em condomínios fechados.

$\mathrm{Na}$ assinatura, o locutor conclui com uma frase que explica a inversão de práticas de gênero na narrativa do comercial: "0 mundo mudou. O Fiat Idea também."

\section{Considerações finais}

Os comerciais são, sem dúvida, surpreendentes e parecem querer anunciar novos tempos - ou, ao menos, acompanhar algumas transformações. Expressões que fecham as peças como "Neuro, evolui", "O mundo mudou" e "A limpeza nunca mais será a mesma" indicam que as empresas anunciantes desejam associar seus produtos a uma ideia de novidade, inovação, evoluçãoe transformação, inclusive nas relações de gênero. Há interesse em ampliar e diversificar públicos: atrair o público masculino, no caso dos produtos de limpeza, e o feminino, no caso do comercial do carro para a família.

Nos três comerciais, algumas transformações de lugares sociais são representadas. A permanência de concepções, práticas e papéis tradicionais de gênero também são notáveis: a falta de jeito do homem para limpeza (logo resolvida com o produto), a manutenção de relações desiguais e hierarquizadas nos casais (invertidos, no caso do comercial do carro, vide comparação com o anúncio da Volkswagen da figura 1) e a performatividade exageradamente masculina, que evita a feminilização de quem usa o produto, no caso do macho Alfa.

Além disso, os personagens dos comerciais se caracterizam como grande parte das pessoas mostradas na publicidade brasileira: branca, magra, jovem e heterossexual, além de uma forte referência à cultura estadunidense, notável no tamanho e no estilo das casas e das cozinhas retratadas. 
As peças contêm alguma ousadia e podem contribuir para a mudança de certos estereótipos de gênero arraigados na cultura brasileira. Se não propõem mudanças bruscas, isso não nos surpreende, pois há limites que a publicidade não ultrapassa; o rompimento completo com o sentido esperado poderia suscitar no público uma aversão imediata ao argumento do comercial. Por meio do humor, as mudanças são apresentadas de modo ambivalente. Por um lado, propõem uma transformação e, por outro, reforçam o modelo de referência ao mostrar essa mudança de forma exagerada.

Se o gênero é um conceito relacional, como afirmou Scott (1986), deve-se notar no comercial do Idea a manutenção de relações desiguais e hierárquicas no que toca à divisão do trabalho entre homens e mulheres. Nessa configuração, apenas o vetor é mudado, mantendo-se a tradicional configuração heteronormativa e a estrutura dicotômica de divisão valorativa de trabalho: o trabalho doméstico pouco valorizado, não remunerado, e o trabalho extra doméstico que confere dinheiro e poder à pessoa que o exerce. Assim, o comercial parece mostrar uma realidade que corresponde àquela interpretação errônea do feminismo: não uma proposta de igualdade, mas de dominação feminina e submissão masculina ("será que eu mereço?").

Os comerciais analisados contribuem para a desnaturalização de certas concepções solidificadas em nossa cultura, ao mostrar o homem como responsável pela casa e o cuidado das crianças, enquanto a mulher é representada como provedora da família ou como uma pessoa que não se importa, nem está encarregada da limpeza da casa. Numa espécie de caricatura das situações, muito comum na publicidade, os comerciais provocam deslocamentos e suscitam a reflexão ao inverter papéis tradicionais. É importante perceber que, nesse caso, o humor não está vinculado ao escárnio, como é comum na abordagem clássica na qual Aristóteles vincula o riso à zombaria e Platão entende que o riso funciona como uma reprovação do vício (MATTOS, 2008). Nesse caso, trata-se muito mais de uma situação inesperada, uma mudança repentina das expectativas, que pode levar a um questionamento da realidade e a uma desnaturalização do olhar.

Se considerarmos que o conjunto de crenças existentes no imaginário de uma sociedade atua de forma coercitiva nas interpretações dos sujeitos, revela-se a importância desses discursos desestabilizadores na publicidade. A partir da ideia de que aquilo que existe fora de nós não pode ser vivido de forma direta e que a linguagem nos fornece quadros de sentido para traduzir o mundo fora de nós, então essas peças publicitárias, na medida em que apresentam maneiras diferentes de "ser homem" e "ser mulher", 
desvinculadas do tradicional discurso machista, enfraquecem a força dessa representação e permitem que formas alternativas sejam oferecidas para os sujeitos contemporâneos. Assim, contribuem para alterar os quadros de sentido que servem de filtros para perceber a realidade.

Vimos que o exagero nas representações reforça o caráter bem-humorado das peças, mostrando que a inversão é, ao mesmo tempo, realidade e brincadeira. Entretanto, nem todo o público achou graça. Nos comentários referentes aos comerciais publicados no YouTube, há muitas reações negativas, principalmente a partir de perfis masculinos, que protestam veemente e agressivamente contra o comercial de carro. A coleta e a análise dos comentários pode ser um caminho proveitoso para a compreensão da recepção dessa e de outras peças, caminho que pode ser seguido em pesquisas futuras sobre gênero e publicidade.

\section{Referências}

AZERÊDO, Sandra. Preconceito contra a "mulher": diferença, poemas e corpos. São Paulo: Cortez, 2007.

BAUDRILLARD, Jean. A sociedade de consumo. Rio de Janeiro: Elfos; Lisboa: Edições 70, 1995.

BEAUVOIR, Simone de. 0 segundo sexo. 2. ed. Rio de Janeiro: Nova Fronteira, 2009.

BRAIDOTTI, Rosi. A política da diferença ontológica. In: BRENNAN, Teresa (Org.). Para além do falo: uma crítica a Lacan do ponto de vista da mulher. Rio de Janeiro: Record, Rosa dos Tempos, 1997. p. 123-144.

BUTLER, Judith. Corpos que pesam: sobre os limites discursivos do "sexo". In: LOURO, Guacira L. (Org.) 0 corpo educado: pedagogias da sexualidade. Belo Horizonte: Autêntica, 1999. p. 151-172.

CORRÊA, Laura Guimarães. Mães cuidam, pais brincam: normas, valores e papéis na publicidade de homenagem. 2011. 254 f. Tese (Doutorado em Comunicação Social) Programa de Pós-graduação em Comunicação Social, Universidade Federal de Minas Gerais, Belo Horizonte, 2011.

MATTOS, Franklin de. Rousseau misantropo - o ridículo na carta a D’Alembert. In: KANGUSSU, Imaculada et al. (Org.) 0 cômico e o trágico. Rio de Janeiro: Editora 7Letras, 2008. p. 11-20.

HISTÓRIA da publicidade e anúncios antigos. 2009. Disponível em: $<$ http://historiadapublicidade.blogspot.com.br/2009/01/propagandas-antigas-defusca.html>. Acesso em: 10 mar. 2014. 
INSTITUTO BRASILEIRO DE GEOGRAFIA E ESTATÍSTICA (IBGE). Pesquisa Nacional por Amostra de Domicílios (PNAD). 2014. Disponível em:

<ftp://ftp.ibge.gov.br/Trabalho_e_Rendimento/Pesquisa_Nacional_por_Amostra_de_Domicil ios_continua/Notas_metodologicas/notas_metodologicas.pdf> Acesso em: 12 mar. 2014.

LOURO, Guacira Lopes. Gênero: questões para a educação. In: BRUSCHINI, Cristina; UNBEHAUM, Sandra (Org.). Gênero, democracia e sociedade brasileira. São Paulo: Editora 34, 2002. p. 225-242.

MEDRADO, Benedito. Homens na arena do cuidado infantil: imagens veiculadas pela mídia. In: ARILHA, M., UNBEHAUM, SG, Medrado, B. (Org.). Homens e masculinidades: outras palavras. 2. ed. São Paulo: Edições 34, 1998. p. 145-161.

MENDES, André. Mapas de Arlindo Daibert: diálogos entre imagens e textos. Belo Horizonte: Editora C/Arte, 2011.

NOVO Fiat Idea 2011: Comercial de lançamento no Brasil. 2010. Disponível em: <http://www.youtube.com/watch?v=irMnhtMVUjU>. Acesso em: 12 mar. 2014

PERROT, Michelle. As mulheres ou os silêncios da história. Bauru, SP: EDUSC, 2005.

SCOTT, Joan. Gender: a useful category of historical analysis. The American Historical Review, Bloomington, v. 91, n. 5, p. 1053-1075, 1986. Disponível em: <http://www.jstor.org/stable/1864376>. Acesso em: 05 mar. 2014.

SODRÉ, Muniz. Por um conceito de minoria. In: PAIVA, Raquel; BARBALHO, Alexandre (Org). Comunicação e cultura das minorias. São Paulo: Paulus, 2005. p. 11-14.

VEJA: Caçadores de Neura em Macho Alfa (2014). Disponível em:

<https://www.youtube.com/watch?v=fw1an6Linkc>. Acesso em: 07 maio 2015.

VEJA: Veja Ação e Proteção em Neuro (2014). Disponível em:

<https://www.youtube.com/watch?v=5L7cGxlpAPU> Acesso em: 07 maio 2015. 


\title{
Inversion, denaturalization and reinforcement of gender practices in advertising
}

\begin{abstract}
The article aims to present a discussion on gender and feminism linked to the analysis of three Brazilian television advertisements which propose practices and discourses that differ from traditional and mostly sexist practices and discourses. The commercials promote cleaning products and a new car model. In these advertisements, women are represented as distant from domestic work people, and the home tasks are performed by men. These are significant changes considering the current gender representations in Brazilian advertising. However, we observe the maintenance of unequal and hierarchical relationships, in which only the vector is changed, maintaining the traditional heteronormative configuration and the dichotomous structure of the gendered division of labor.
\end{abstract}

\section{Keywords}

Advertising. Feminism. Division of labor. Gender practices.

Recebido em: 26/06/2014

Aceito em: 16/03/2015 